\title{
Influence of Surface Contamination of Conductor on Positive Corona-Generated Audible Noise Spectrum Characteristics of HVDC System
}

\author{
Yong $\mathrm{YI}^{1,2}$, Chuyan ZHANG ${ }^{2}$, Yuanjiu WANG ${ }^{1,2}$, Zhengying $\mathrm{CHEN}^{1,2}$, Liming $\mathrm{WANG}^{2}$ \\ 1. Department of Electrical Engineering, Tsinghua University, Beijing, China \\ 2. Graduate School at Shenzhen, Tsinghua University, Shenzhen, China \\ yiyongshanxi@126com
}

\begin{abstract}
Surface contamination of high-voltage directcurrent power transmission lines has a large influence on corona characteristics. The audible noise of the polluted conductors is much higher than clean conductors. Little is known about the effect of the surface conditions of conductors on spectrum characteristics of the positive corona-generated audible noise under a high voltage. In order to investigate the influence of surface contamination produced by atmospheric pollution on the spectrum of the audible noise, this paper presented the measurement of spectrum characteristics of the audible noise of positive corona discharge in a laboratory corona cage. We researched the influence of deposition and relative permittivity of the contamination on the spectrum characteristics of the positive corona-generated audible noise. The relationships among these factors were consequently acquired. The results revealed that the spectral components of the audible noise of clean conductor were obviously different with the increase of the applied voltage. The spectral components $(>1 \mathrm{kHz})$ of the polluted conductors were much higher than those of the clean conductors. The contamination adhering to the surface of conductors affected spectral components $(>1 \mathrm{kHz})$ much more obviously than low spectral components, and the results were analyzed in this paper. The conclusion lays a foundation for researching the influence of the surface conditions on the corona-generated audible noise.
\end{abstract}

Keywords-audible noise; spectrum characteristics; contamination; corona cage; HVDC; positive corona discharge

\section{INTRODUCTION}

High voltage direct current (HVDC) and ultra-high voltage direct current (UHVDC) power transmission lines have been set up in China over recent years and these lines were employed to delivery energy over long distances [1]. The corona characteristics is an important technical problem among high voltage power engineers, which could cause corona loss $(\mathrm{CL})$, radio interference (RI) and audible noise (AN). So, for these reasons, the corona-generated electromagnetic environment problem of HVDC power transmission line is an main design and operation consideration[2].

The audible noise was studied by the acoustic and mathematics modeling in the earlier years [3-6]. Then, researches about the audible noise were mainly developed for the prediction of audible noise of high voltage transmission lines by A-weighted empirical formulas. Based on the test lines and outdoor corona cage, BPA and CRIEPI develop empirical formulas of noise prediction, respectively [7-8]. However, conductor surface conditions effects on audible noise were not considered in these prediction empirical formulas.

Many researchers studied that the surface conditions of aged conductors by scanning electron microscopy (SEM) and three dimension Phase Shift Micro-Xam(MicroXAM-3D). Using these devices, the surface morphology, composition and roughness of the aged conductors were measured and analyzed [9]. In time domain, it was found that the instantaneous sound pressure pulses and the corona current pulses had the one-toone relationship and repetitive frequency in time. The peak values of instantaneous sound pressure pulses had a linear correlation with the amplitude of corona current pulses [10]. However, less attention has been paid to the relationship between the spectrum characteristic of the audible noise and surface conditions of the polluted conductor in frequency domain.

According to previous literature, the audible noise of the positive corona discharge has higher sound pressure level than that produced by negative corona. Hence, the positive corona discharge was mainly focused on in our work.

The present paper investigates the influence of contamination of conductor on noise spectrum characteristics of positive corona discharge. The artificial contamination, deposited on the surface of conductors, was composed of salt, kaolin, and carbon. When the surface of the conductors was covered with salt, kaolin and carbon, respectively, the spectrum of polluted conductors was measured and recorded under different positive DC voltage. Finally, the correlation between the surface pollution and audible noise spectrum were studied and analyzed.

\section{TEST SETUP AND MEASUREMENT}

\section{A. Indoor Corona Cage}

An indoor corona cage was manufactured to measure the spectrum characteristics of the polluted conductors in our laboratory. Figure.1 presents the audible noise measurement experimental platform. Figure. 2 shows the general view of the indoor corona cage. The diameter of conductor is $0.01 \mathrm{~m}$. The conductor is placed concentrically inside the corona cage. The 
total length of the cage is $2 \mathrm{~m}$. It consists of a $1.4 \mathrm{~m}$ length measurement section for corona audible noise measurement and two $0.3 \mathrm{~m}$ length guard sections to eliminate the end region behavior. The cross section of the cage is square and its dimension is $0.8 \mathrm{~m} \times 0.8 \mathrm{~m}$.

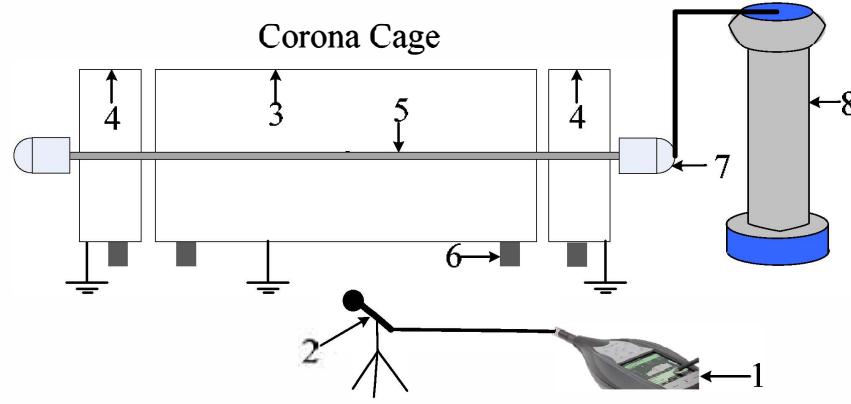

1Sound level meter, 2Microphone, 3Measurement section, 4Guard section, 5Conductor, 6 Plastic insulator, 7 Corona ring, 8High voltage source

Fig. 1. Schematic diagram of the experimental platform

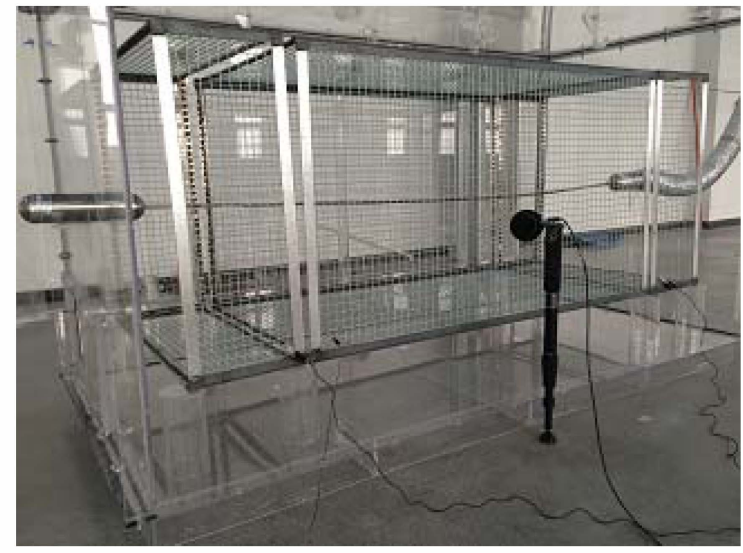

Fig. 2. General view of the indoor corona cage in our laboratory

All the measurements were carried out when the temperature was in the range of 20 to $22^{\circ} \mathrm{C}$. The air pressure was between 100.1 to $100.3 \mathrm{kPa}$ and the relative humidity was between $19 \%$ to $21 \%$. The environmental noise is less than $21.1 \mathrm{~dB}$ (Aweighted) in the electromagnetic environment simulation laboratory.

\section{B. Audible noise test arragement}

In the experiment, sound level meter Brüel \& Kjær 2250L is used to test the sound pressure level, which is a modular Class I sound level meter and could measure all standard acoustic parameters simultaneously. The 2250L sound meter also has the functions of spectrum measurement and frequency analysis, as shown in Figure.3. The BK pre-polarized free-field $1 / 2$ inch microphone has a $5.6 \mathrm{~Hz}$ to $20 \mathrm{kHz}$ broadband linear frequency range and $16.4 \mathrm{~dB}$ to $140 \mathrm{~dB} \mathrm{~A}$-weighted dynamic range. The sensitivity of the microphone is $50 \mathrm{mV} / \mathrm{Pa}$. So, the microphone is suited for high-precision corona noise measurement. The sound signal is converted into an equivalent electric signal by the microphone. Then, the low level electric signal is made stronger by the preamplifier before it is finally processed by the sound level meter.

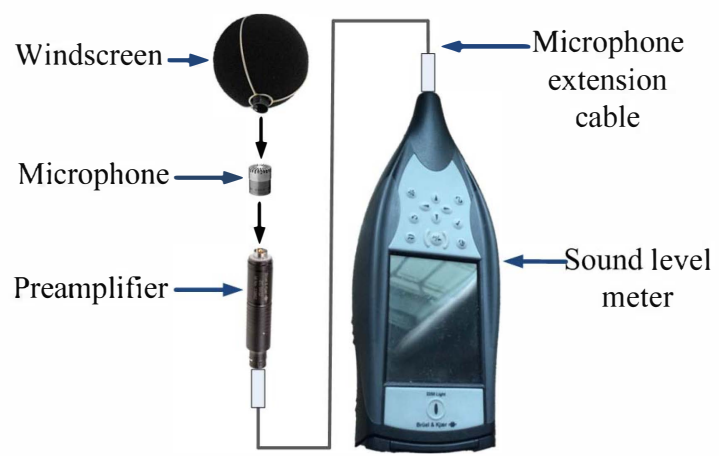

Fig. 3. Hand-held sound level meter type 2250L

\section{Polluted Conductors}

The pollution characteristics of the conductor were examined with a pollution experiment, which simulated the contamination deposition process by applying a positive DC voltage. The pollution, deposited on the surface of the conductor, was composed of salt, kaolin, and carbon, respectively. Figure. 4 shows the pictures of the bare, salt-, kaolin- and carbon-polluted conductors, respectively. (a)

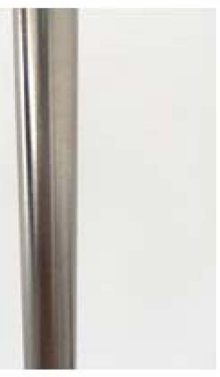

(c)

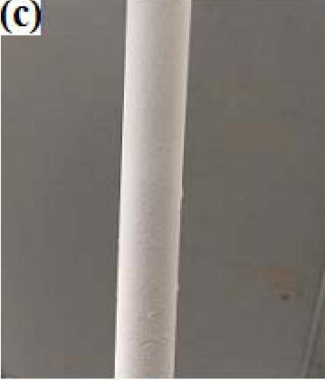

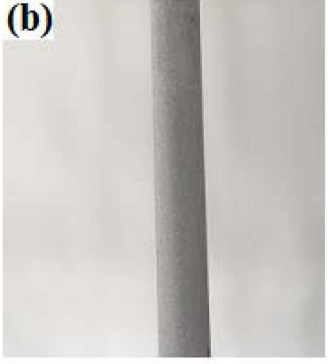

(d)

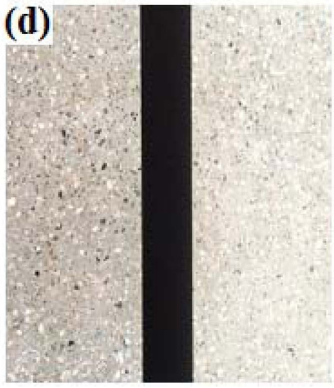

(a) Bare conductor (b) Salt-polluted conductor (c) Kaolin-polluted conductor (d) Carbon-polluted conductor

Fig. 4. Pictures of bare, salt-, kaolin-, carbon-polluted conductors

\section{TEST RESULTS AND ANALYSIS}

\section{A. Typical Corona Discharge of The Bare and Polluted Conductors}

Figure.5 presents the UV characteristics of typical corona discharge of bare conductor and the polluted conductors. Compared with the bare conductor, the photon emitted from corona discharges on the surface of the polluted conductors was much greater and the area of the corona discharge detected much larger, under the same positive DC voltage. 

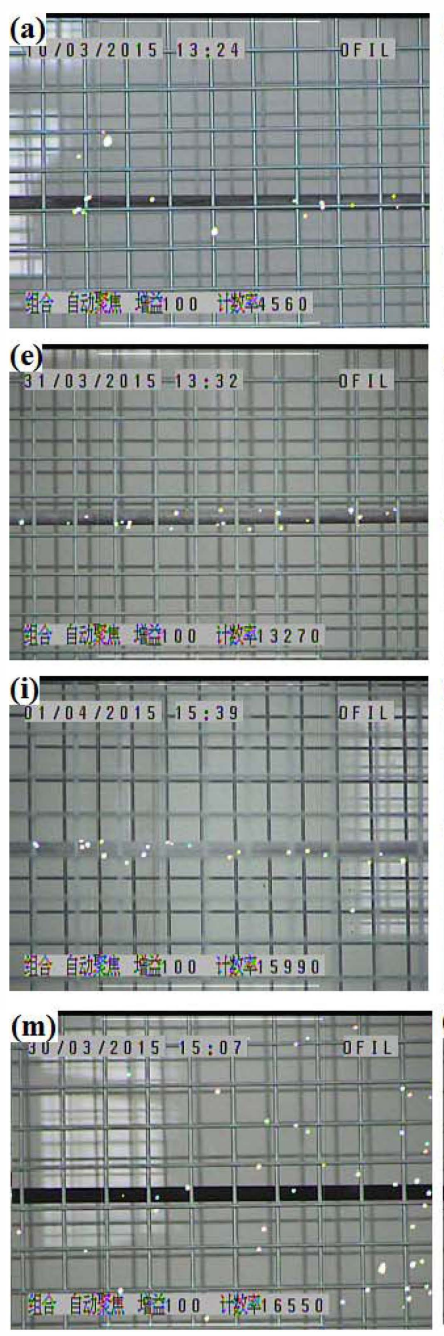
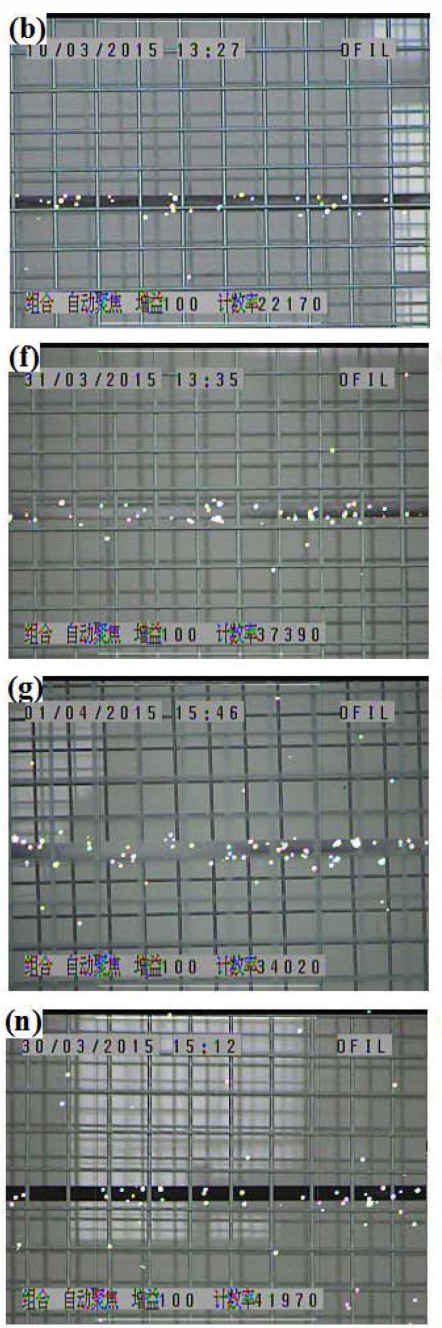
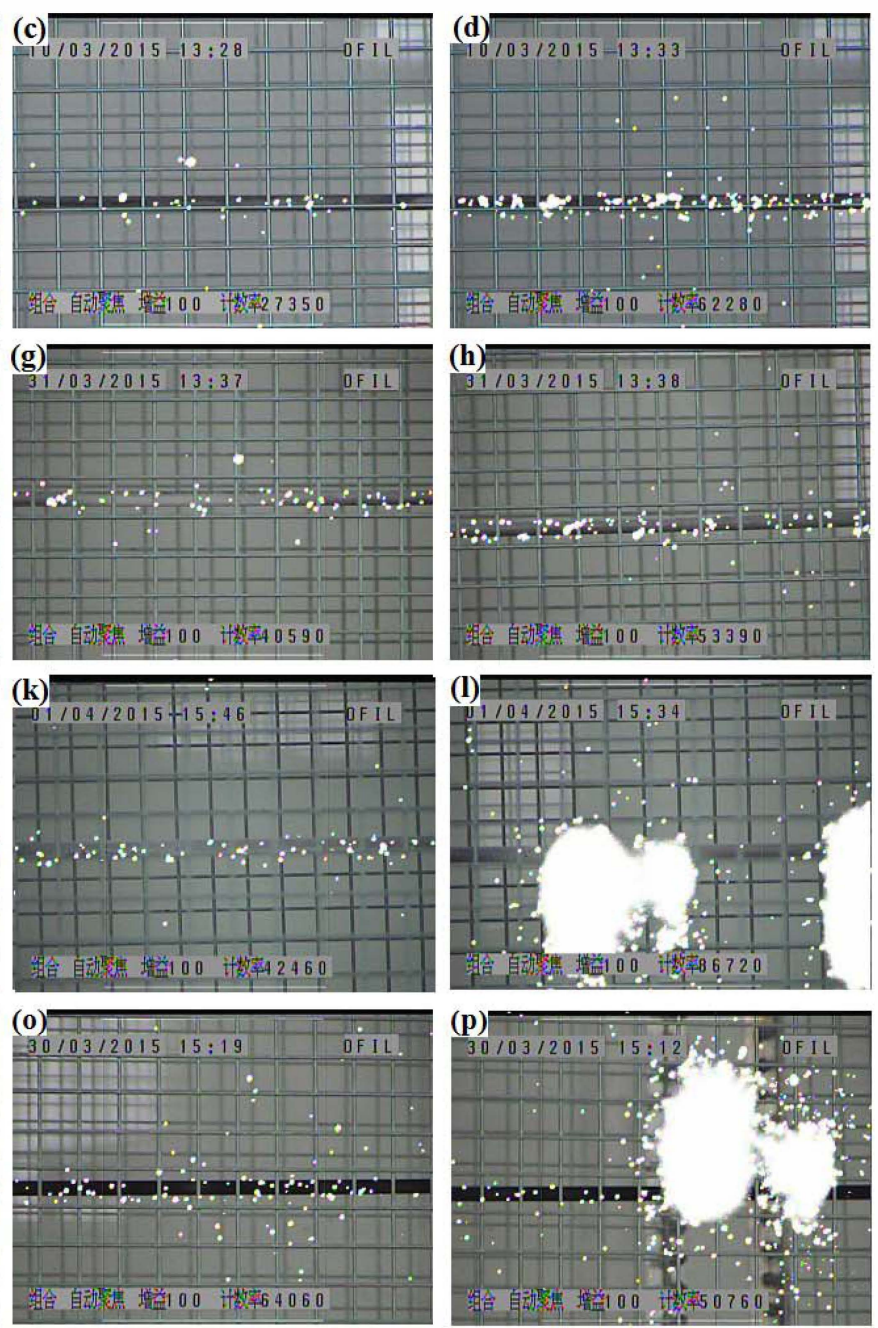

(a)-(d) Typical corona discharge of the bare conductor (e)-(h) Typical corona discharge of the salt-polluted conductor (i)-(l) Typical corona discharge of the kaolin-polluted conductor (m)-(p) Typical corona discharge of the carbon-polluted conductor

Fig. 5. Typical corona discharge of the bare, salt-, kaolin-, carbon-polluted conductor under $100 \mathrm{kV} 、 105 \mathrm{kV} 、 110 \mathrm{kV} 、 115 \mathrm{kV}$

\section{B. Audible Noise Spectrum of The Bare and Polluted Conductors}

The equivalent continuous sound level (ECSL) is used to evaluate the acoustic noise, which is known as the essential averaged parameter, The ECSL is defined by

$$
\operatorname{Leq}(T)=20 \lg \left[\sqrt{1 / \Delta t \int_{T}^{T+\Delta t} p_{x}^{2}(\zeta)} / p_{0}\right]
$$

Where $\zeta$ is a dummy variable of time integration; $p_{x}(\zeta)$ is the $\mathrm{A}, \mathrm{B}, \mathrm{C}$ or $\mathrm{Z}$ frequency-weighted instantaneous sound pressure; $p_{0}=20 \mathrm{uPa}$ is the reference sound pressure. $\Delta t$ is the average time interval.

Figure 6 presents the audible noise spectrum of bare conductor under the positive voltage. The horizontal ordinate of the figure is $1 / 3$-octave band center frequencies.

Figure 7 shows that the audible noise spectra of bare, salt-, kaolin- and carbon-polluted conductor were measured under $105 \mathrm{kV}, 110 \mathrm{kV}$ and $115 \mathrm{kV}$, respectively and the results of the audible noise spectra of kaolin-polluted conductor with deposition density of $0.5 \mathrm{mg} / \mathrm{cm}^{2}, 1.0 \mathrm{mg} / \mathrm{cm}^{2}$ and $2.0 \mathrm{mg} / \mathrm{cm}^{2}$, respectively.

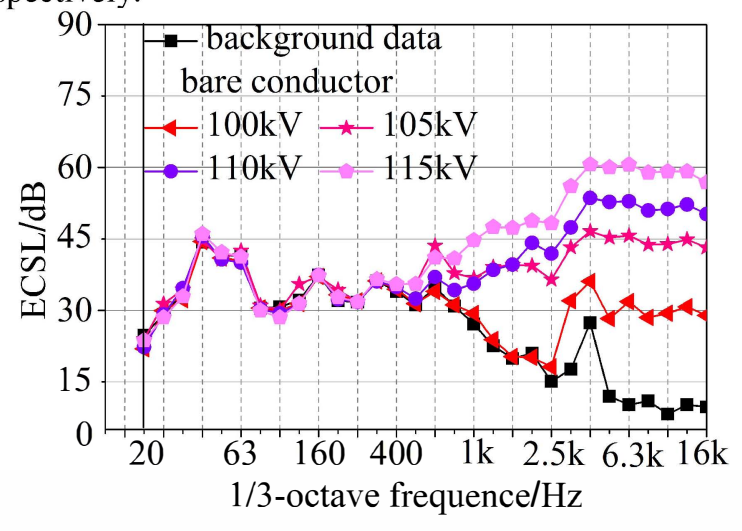

Fig. 6. The spectrum of audible noise of bare conductor

From the results of the typical corona discharge of the bare, salt-, kaolin- and carbon-polluted conductors, it was observed that the intensity of the corona discharge increased in the order of the bare, salt-, kaolin- and carbon-polluted conductors. 

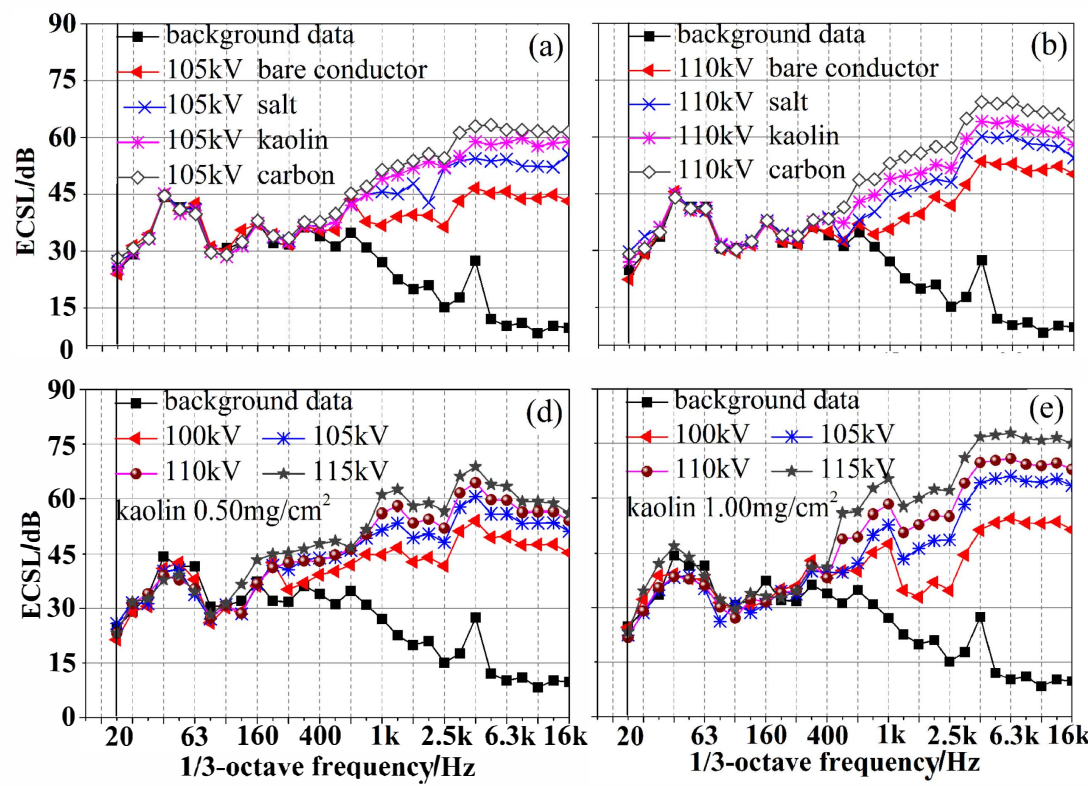
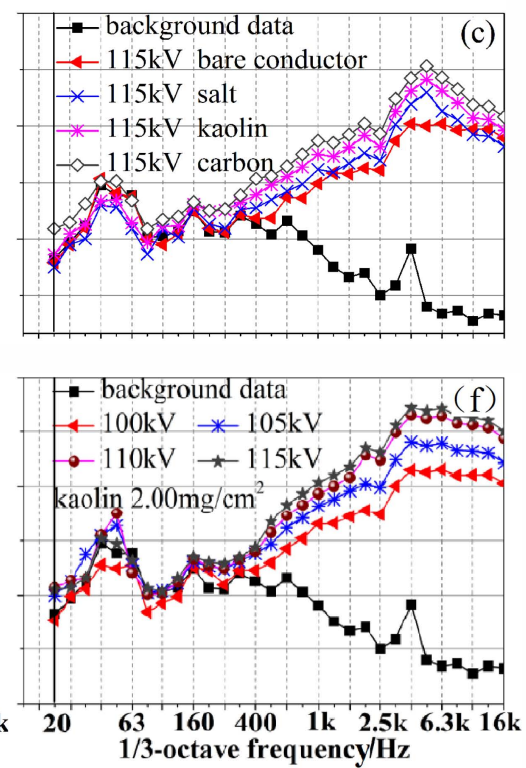

(a) -(c) Audible noise spectra of bare, salt-, kaolin-, carbon-polluted conductor under $105 \mathrm{kV}, 110 \mathrm{kV}$ and $115 \mathrm{kV}$, respectively (d) -(f) Audible noise spectra of kaolin-polluted conductor with deposition density of $0.5 \mathrm{mg} / \mathrm{cm} 2,1.0 \mathrm{mg} / \mathrm{cm} 2 \mathrm{and} 2.0 \mathrm{mg} / \mathrm{cm} 2$ Figure 7. Audible noise spectrum characteristics of the polluted conductor

Compared with the bare conductor, the photon counting rate of the polluted conductors increased obviously under the same positive DC voltages. With the intensity of the corona discharge increased, the audible noise increased obviously.

From the spectrum results of the polluted conductors, it is found that the spectral components $(>1 \mathrm{kHz})$ of the polluted conductor have an obvious increasing trend as the applied voltage increases. The spectral components $(<1 \mathrm{kHz})$, especially less than $125 \mathrm{~Hz}$, have an unobvious increasing trend with the surface potential gradient.

The audible noise spectra $(<125 \mathrm{~Hz})$ of the polluted conductor are consistent with the environment noise and almost unchanged with the applied voltage. The audible noise spectra $(>1 \mathrm{kHz})$ increase with the increase of the amount of pollution and the relative permittivity.

Furthermore, from the results of the long-term statistical measurement about A-weighted ECSL (LAeq) of the polluted conductor, the spectral components $(>1 \mathrm{kHz})$ of the polluted conductor have an obvious increasing trend as the applied voltage. While, the spectral components $(<1 \mathrm{kHz})$, especially less than $125 \mathrm{~Hz}$, have an unobvious increasing trend with the applied voltage.

\section{CONCLUSION}

Based on the indoor corona cage, the audible noise experiment platform was set up to obtain the relationship between the surface pollution of the conductors and the audible noise spectrum generated by positive corona discharge. The artificial pollution experiments were carried out to simulate the various surface conditions.

It was found that the audible noise level increased as the amount of pollution increased. In addition, as the relative permittivity grew, the corona noise and current increased obviously.

\section{ACKNOWLEDGMENTS}

The authors acknowledge the financial support from the key Project of National Basic Research Program of China (2011CB209406) and National Natural Science Foundation of China (51377096).

\section{REFERENCES}

[1] P. S. Maruvada, Corona Performance of High Voltage Transmission Lines, Taylor \& Francis Group, 2000.

[2] M. Abdel-Salam, High voltage engineering-theory and practice, Marcel Dekker Press, 2000.

[3] $\mathrm{Ph}$. Béquin, K. Castor, Ph. Herzog and V. Montembault, "Modeling plasma loudspeakers", J. Acoust. Soc. Am. Vol. 121, No.4, pp. 19601969, 2007.

[4] K. Matsuzawa, "Sound Sources With Corona Discharges", J. Acoust. Soc. Am, Vol. 54, No.2, pp. 495-498, 1973.

[5] F. Bastien, "Acoustic and gas discharges: applications to loudspeakers", J. Phys. D: Appl. Phys. Vol. 20, pp. 1547-1557, 1987.

[6] Ph. Béquin, V. Joly and Ph. Herzog, "Modeling of a corona discharge microphone", J. Phys. D: Appl. Phys. Vol.46, 175204, 2013.

[7] V. L. Chartier and R. D. Stearns, "Formulas for prediction audible noise from overhead high voltage AC and DC lines", IEEE Trans. Power App. Syst., Vol.100, No.1, pp.121-129, 1981.

[8] Yukio, Yoshitaka Sunaga, "Availability of corona cage for predicting audible noise generated from HVDC transmission line", IEEE Trans. Power Del., Vol. 4, pp.1422-1431,1989.

[9] X. M. Bian, D.M. Yu, L. Chen, J. M. K. MacAlpine, L. M. Wang, Z. C. Guan and F. D. Chen, "Influence of aged conductor surface conditions on AC corona discharge with a corona cage", IEEE Trans. Dielectr. Electr. Insul., Vol.18, pp. 809-818, 2011.

[10] Xuebao Li, Xiang Cui, Tiebin Lu, Yang Liu, Di Zhang and Zhenguo Wang, "The Correlation between Audible Noise and Corona Current in Time Domain Caused by Single Positive Corona Source on the Conductor", IEEE Trans. Dielectr. Electr. Insul., Vol.22, pp. 13141319,2015 